\title{
Analysis of the planned, delivered dose distributions and quality assurance for helical tomotherapy and volumetric modulated arc therapy in locally advanced non-small cell lung cancer
}

\author{
Pitchayaponne Klunklin ${ }^{1,2}$, Tamisa Manoharn ${ }^{1}$, Somsak Wanwilairat ${ }^{1}$, Wannapha Nobnop ${ }^{1,2}$, \\ Anirut Watcharawipha ${ }^{1}$ Imjai Chitapanarux ${ }^{1,2}$ \\ ${ }^{1}$ Division of Radiation Oncology, Department of Radiology, Faculty of Medicine, Chiang Mai University, Chiang Mai, Thailand \\ ${ }^{2}$ Northern Thai Research Group of Radiation Oncology (NTRG-RO), Faculty of Medicine, Chiang Mai University, Chiang Mai, Thailand
}

\begin{abstract}
Background: With full access to both helical tomotherapy (HT) and volumetric modulated arc therapy (VMAT), we compared locally advanced non-small cell lung cancer (LA-NSCLC) treatment plans and verified the plans using patient-specific pretreatment quality assurance (PSQA).

Materials and methods: For each of the seventeen patients included in the study, two treatment plans (i.e. HT and VMAT) were created. Optimized plans were evaluated following the ICRU 83 criteria. Planned quality indexes and dosimetric parameters were compared. Lastly, all plans were subjected to PSQA assessment by determining the gamma passing rate (GPR).

Results: All dosimetry results obtained from the planning target volume passed the ICRU 83 criteria. With regard to similar homogeneity indices, VMAT produced better conformity number values than $\mathrm{HT}(0.78 \mathrm{vs} .0 .64)$, but differences in the values were insignificant. Furthermore, VMAT was associated with a significantly shorter mean treatment time (1.91 minutes vs. 6.66 minutes). For PSQA assessment, both techniques resulted in adequate GPR values (>90\% at the $3 \% / 3 \mathrm{~mm}$ criteria).

Conclusion: Both HT and VMAT techniques led to the generation of clinically satisfactory and reliable radiotherapy plans. However, the VMAT plan was associated with a non-significantly better degree of conformity and a significantly shorter treatment time. Thus, VMAT was determined to be a better choice for LA-NSCLC.
\end{abstract}

Key words: helical tomotherapy (HT); volumetric modulated arc therapy (VMAT); lung cancer; dosimetric comparison; patientspecific pretreatment quality assurance (PSQA)

Rep Pract Oncol Radiother 2021;26(6):939-947

\section{Introduction}

Radiotherapy and chemotherapy are standard forms of treatment for cases of locally advanced non-small cell lung cancer (LA-NSCLC). For many decades, radiotherapy has proven to be an effective method of treatment. It has been associated with a number of beneficial outcomes including the survival rate among patients of this disease [1,2]. With an expanded knowledge of radiation physics and the development of related appliances over time, a number of modern radiation techniques can now

Address for correspondence: Pitchayaponne Klunklin, M.D., Division of Radiation Oncology, Faculty of Medicine, Chiang Mai University, 110 Intavaroros Road, Sriphum, Muang, Chiang Mai, Thailand, 50200, tel: +66846092813, fax: +665393549; e-mail: pitchayaponne.kl@cmu.ac.th 
be used to treat NSCLC. All of these modern techniques operate with the essential goal of maximizing tumor control and minimizing toxicity.

Although three-dimensional conformal radiotherapy (3DCRT) remains a minimum standard option for LA-NSCLC treatment, intensity-modulated radiotherapy (IMRT), which is a more advanced radiation technique, has become even more popular. One prospective trial showed similar 2-year local control results and similar overall survival rates for 3DCRT and IMRT; however, IMRT produced significantly lower rates of severe radiation pneumonitis and cardiac doses. This was evident even for trial involving greater numbers of stage IIIB patients, larger planning treatment volumes (PTV), and a larger PTV/volume of lung ratio [3]. Subsequently, the authors of this study have recommended the routine administration of IMRT for LA-NSCLC.

With the use of complex modulated radiation beams that adjust the dose to conform to the target, IMRT has been found to produce excellent results in terms of sparing the organs at risk (OARs) by providing sharp dose gradients between the targets and OARs. Additionally, recent IMRT techniques, that have utilized more sophisticated planning methods and machines, namely helical tomotherapy (HT) and Volumetric Modulated Arc Therapy (VMAT), have yielded a better degree of dose distribution and a better degree of OARs sparing when compared to either IMRT or 3DCRT $[4,5]$.

With regard to radiation treatment, HT can deliver various sizes of thin intensity-modulated fan beams from a rotating gantry as the treatment couch moves the patient synchronously through the bore. This differs significantly from the conventional IMRT techniques that deliver wider intensity-modulated beams to a static patient [6]. With much higher numbers of beams emitted from the rotating gantry, HT has had an advantage over fixed-field IMRT systems by generating a better conformal dose to the target while avoiding radiation exposure to normal organs [7].

VMAT is a modern type of rotational IMRT that uses gantry rotation of up to 360 degrees to move around the patient with simultaneous and dynamic modulation of gantry speed, multileaf collimator (MLC) motion, and dose rate. All of which allows this technique to deliver an intensified radiation beam [8]. While capable of delivering a treatment that would require 7-9 IMRT fields in a single arc or two arcs, VMAT can shorten treatment time to less than five minutes in contrast to the 10-15 minutes that are required for fixed-field IMRT techniques. When compared to the conventional IMRT systems that are commonly employed in different solid cancer treatments, VMAT has been associated with improved degrees of dose conformity and OARs sparing [9-11].

Nowadays, there is scattered evidence on the clear advantages of one particular IMRT technique over another in LA-NSCLC, while a set of consensus guidelines for treatment technique selection is still not available. Our institute has access to both HT and VMAT as the necessary equipment was installed in 2012 and 2017, respectively. Consequently, we have conducted this prospective trial with the intent of comparing LA-NSCLC plan analysis and quality assurance (QA) assessment of both IMRT techniques. The results of this trial can provide researchers with specific details about the advantages and drawbacks of each technique. Knowledge of these details can assist health care professionals in their treatment technique selection process.

\section{Materials and methods}

After being reviewed and approved of by the local ethics committee, this prospective trial included 17 LA-NSCLC patients who were scheduled for treatment with radical radiotherapy or concurrent chemoradiation in our department. All patients were pathologically confirmed as having non-small cell lung carcinoma and were staged according to the $8^{\text {th }}$ edition of the American Joint Committee on Cancer (AJCC) staging system for lung cancer. Informed consent forms were signed and obtained from all patients.

\section{Simulation, target delineation, and dose prescription}

Four-dimensional computed tomography (4DCT) simulation using SOMATOM Definition AS (Siemens Medical Solutions, Erlangen, Germany) and a Respiratory Gating System (AZ-733VI Rev.1.0 by Ansai Medical, Co., Ltd., Shinagawa-Ku, Japan) was used for all patients. Subjects were asked to remain in a supine and arm-up position on a lung-board with free breathing. CT imagining with intravenous contrast began from the mandible 
and continued through the liver with a thickness of $5 \mathrm{-mm}$. The images were transferred to the contouring workstation (Oncentra Master Plan version 4.3, Elekta $A B$, Stockholm, Sweden), and a single radiation oncologist delineated both the target volumes and the OARs for all cases. The gross tumor volume (GTV) included primary lung lesions and enhanced thoracic lymph nodes that were enlarged to $\geq 1 \mathrm{~cm}$ in a short-axis diameter from the contrast-enhanced CT or PET/CT imaging. The GTV was contoured from a maximum intensity projection image (MIP) that had been reconstructed from a 4D-CT scan and then rechecked with all ten phases of the image data set to establish internal GTV (iGTV). The internal clinical target volume (iCTV) was produced by expanding the $6-8 \mathrm{~mm}$ margin around iGTV and the planning target volume (PTV) was created by expanding the $5 \mathrm{~mm}$ margin around iCTV. A total dose of $60 \mathrm{~Gy}$ by conventional fractionation ( $2 \mathrm{~Gy} /$ fraction) was prescribed to cover the PTV. The spinal cord, right and left lungs, heart, and esophagus were outlined on the average image of the 4DCT scans as OARs [12].

\section{Treatment planning}

The HT and VMAT plans were generated by single dosimetrist using HiArt v.4.1.2 (Accuray, Sunyvalle, CA, USA) and Monaco v 5.11 (Elekta, Stockholm, Sweden) treatment planning systems, respectively. A field width of $2.51 \mathrm{~cm}, 0.287$ pitch, 3-3.5 modulation factors, and $850 \mathrm{MU} / \mathrm{min}$ dose rates were used for HT planning. The VMAT plan used a technique involving two partial arcs that was designed to correspond with the tumor location in the lungs in order to avoid delivering a high dose to the OARs. For the structure prioritization, the order for each case varied depending on the types of OARs that were close to the tumor. However, the organ priority was the same for both the HT and VMAT plans. The final dose distribution was calculated by the Collapsed cone convolution algorithm with a grid spacing of $2.5 \mathrm{~mm}$ for $\mathrm{HT}$ and the XVMC Monte Carlo algorithm with a grid spacing of $3 \mathrm{~mm}$ for VMAT.

\section{Planning evaluation}

Results of the dose-volume histograms (DVHs) for the PTV and OARs were used to evaluate the quality of the plans and to compare any dosimetric differences between the 2 IMRT techniques. The target coverage was assessed by following three specific points of criteria taken from the International Commission on Radiation Units and Measurements (ICRU) report 83:

$95 \%$ of the prescribed dose ( $5700 \mathrm{cGy}$ ) covered at least $98 \%$ of the PTV volume $\left(\mathrm{V}_{95} \geq 98 \%\right)$.

At least $50 \%$ of the PTV volume was covered by the prescribed dose $\left(D_{50 \%} \geq 60 \mathrm{~Gy}\right)$.

$107 \%$ of the prescribed dose ( $6420 \mathrm{cGy}$ ) covered less than $2 \%$ of the PTV volume $\left(\mathrm{V}_{107} \leq 2 \%\right)$.

The homogeneity index (HI) [13] and conformity number $(\mathrm{CN})[14]$ were also used to evaluate the precision of the dose distribution to the PTV.

$$
H I=\frac{D 2-D 98}{D p}
$$

D2 and D98 represent doses of 2 and $98 \%$ of the PTV volume, respectively, while Dp represents the prescribed dose. Values of HI that were closer to 0 indicated greater dose homogeneity within the PTV.

$$
C N=\frac{V T, r e f}{V T} \times \frac{V T, r e f}{V r e f}
$$

VT,ref is defined as the volume of the PTV receiving a dose equal to or greater than the prescribed dose. VT represents the PTV volume and $\mathrm{V}_{\text {ref }}$ represents the volume receiving a dose equal to or greater than the prescribed dose (treated volume). $\mathrm{CN}$ is valued between $0-1$ and values of $\mathrm{CN}$ closer to 1 indicated a better isodose covering the PTV volume and a lesser radiation dose when compared to normal tissue.

The maximum dose, mean dose, and dose-volume limits to the OARs (spinal cord, lungs, heart, and esophagus) were collected. OARs dose specification criteria obtained from RTOG 0617 [15] were used to evaluate the plans. Total treatment times for each plan based on the expectation from the planning program were gathered as well.

After completion of the treatment planning process, all plans were subjected to a patient-specific pretreatment quality assurance (PSQA) assessment. The gamma index analysis was evaluated using an ArcCHECK (Sun Nuclear Corporation, Melbourne, FL) diode array detector system in order to measure the accuracy of each plan [16]. The $3 \%$ dose difference $/ 3 \mathrm{~mm}$ distance $(3 \% / 3 \mathrm{~mm})$ parameters of the absolute and relative radiation doses were calculated. This treatment was determined to be accept- 
able in terms of accuracy if the gamma passing rate (GPR) was more than $90 \%[17,18]$.

With regard to the actual treatment for each patient, treatment plans for both techniques were approved for use depending upon the treatment queue for our institute.

\section{Statistical analysis}

All radiation dose data collected from the HT and VMAT treatment plans were analyzed and reported as mean \pm standard deviation (SD) values. The Wilcoxon signed ranks test was used to compare all dosimetric parameters and GPR values of the two plans. In terms of planning system accuracy and related clinical significance, the lower threshold at a value of $p<0.01$ was considered to be of statistical significance. Statistical analysis was performed using SPSS statistical software version 26 (Chicago, Illinois, USA).

\section{Results}

Seventeen patients were included in this trial. Most patients (41.18\%) were diagnosed with NSCLC stage IIIC according to AJCC lung cancer staging $8^{\text {th }}$ edition. The mean age of the subjects was 65.71 years and the median PTV volume was $424.51 \mathrm{ml}$ (range 146.34-1379.34 mL). Table 1 shows the characteristics of the patients, staging, and PTV volumes.

Thirty-four treatment plans were generated by only one dosimetrist following our protocol. In terms of target coverage, both the HT and VMAT plans met all of the clinical requirement criteria. Each dosimetric parameter of PTV is shown in Table 2 without any statistically significant differences observed between the two techniques. When $\mathrm{HI}$ values were evaluated, the HT and VMAT plans displayed almost identical HI values. However, the VMAT plans revealed $\mathrm{CN}$ values that were better (but statistically insignificant) than those of the HT plans (0.78vs. $0.64, \mathrm{p}=0.01)$.

With regard to the radiation dose to the OARs, every treatment plan was within the target dose limitation according to the OARs dose specification criteria obtained from RTOG 0617 . When comparing the two techniques, the integral dose and the radiation dose to the lungs, heart, spinal cord, and esophagus did not exhibit any statistically significant differences (Tab. 2). Additionally, we collected
Table 1. Patient characteristics

\begin{tabular}{|c|c|c|}
\hline Characteristics & N & $\%$ \\
\hline $\begin{array}{l}\text { Age [year] } \\
\text { Mean } \pm \text { SD } \\
\text { Range }\end{array}$ & $\begin{array}{l}65.71 \pm 6.98 \\
50.35-77.65\end{array}$ & \\
\hline $\begin{array}{l}\text { Sex } \\
\text { Male } \\
\text { Female }\end{array}$ & $\begin{array}{l}12 \\
5\end{array}$ & $\begin{array}{l}70.59 \\
29.41\end{array}$ \\
\hline $\begin{array}{l}\text { Staging grouping } \\
\text { IIIA } \\
\text { IIIB } \\
\text { IIIC }\end{array}$ & $\begin{array}{l}4 \\
6 \\
7\end{array}$ & $\begin{array}{l}23.53 \\
35.29 \\
41.18 \\
\end{array}$ \\
\hline $\begin{array}{l}\text { T staging } \\
\text { T1 } \\
\text { T2 } \\
\text { T3 } \\
\text { T4 }\end{array}$ & $\begin{array}{l}2 \\
1 \\
6 \\
8\end{array}$ & $\begin{array}{c}11.77 \\
5.88 \\
35.29 \\
47.06\end{array}$ \\
\hline $\begin{array}{l}\text { N staging } \\
\text { N0 } \\
\text { N1 } \\
\text { N2 } \\
\text { N3 }\end{array}$ & $\begin{array}{c}1 \\
0 \\
6 \\
10\end{array}$ & $\begin{array}{c}5.88 \\
0 \\
35.29 \\
58.83 \\
\end{array}$ \\
\hline $\begin{array}{l}\text { Primary tumor location } \\
\text { RUL } \\
\text { RML } \\
\text { RLL } \\
\text { LUL } \\
\text { LLL }\end{array}$ & $\begin{array}{l}6 \\
2 \\
2 \\
4 \\
3\end{array}$ & $\begin{array}{l}35.29 \\
11.77 \\
11.77 \\
23.53 \\
17.64\end{array}$ \\
\hline $\begin{array}{l}\text { Pathology } \\
\text { Adenocarcinoma } \\
\text { Squamous cell carcinoma } \\
\text { Other }\end{array}$ & $\begin{array}{c}11 \\
5 \\
1\end{array}$ & $\begin{array}{c}64.71 \\
29.41 \\
5.88 \\
\end{array}$ \\
\hline $\begin{array}{l}\text { PTV volume }[\mathrm{mL}] \\
\text { Median } \\
\text { Range }\end{array}$ & $\begin{array}{c}424.51 \\
146.34-1379.34\end{array}$ & \\
\hline
\end{tabular}

$\mathrm{SD}$ — standard deviation; RUL — right upper lobe; RML — right middle lobe; RLL — right lower lobe; LUL — left upper lobe; LLL — left lower lobe; PTV — plannning treatment volume

data on the treatment time for each patient (Fig. 1) and noticed that the HT plans utilized significantly longer mean beam-on times than the VMAT plans (6.66 and 1.91 minutes, $\mathrm{p}<0.001$, respectively).

In terms of the gamma index analysis by ArcCHECK system, all the HT and VMAT plans revealed that the GPR at $3 \% / 3 \mathrm{~mm}$ level exceeded $90 \%$ for both the absolute and relative doses (Fig. 2).

\section{Discussion}

Regarding radiation treatment in LA-NSCLC, IMRT is accepted as a standard modality. However, 
Table 2. Dosimetric parameters of plannning treatment volume (PTV) and organs at risk (OARs) (mean \pm SD)

\begin{tabular}{|c|c|c|c|}
\hline Parameters & Helical tomotherapy & $\begin{array}{c}\text { Volumetric modulated } \\
\text { arc therapy }\end{array}$ & p-value \\
\hline $\mathrm{D}_{2 \%}[\mathrm{~Gy}]$ & $63.12 \pm 0.36$ & $63.22 \pm 0.42$ & 0.472 \\
\hline $\mathrm{D}_{50 \%}[\mathrm{~Gy}]$ & $61.10 \pm 0.32$ & $61.34 \pm 0.31$ & 0.066 \\
\hline $\mathrm{D}_{98 \%}[\mathrm{~Gy}]$ & $57.36 \pm 0.20$ & $57.52 \pm 0.33$ & 0.078 \\
\hline $\mathrm{V}_{95}(\%)$ & $98.55 \pm 0.23$ & $98.50 \pm 0.27$ & 0.136 \\
\hline $\mathrm{V}_{107}(\%)$ & $0.13 \pm 0.16$ & $0.28 \pm 0.36$ & 0.147 \\
\hline Homogeneity index & $0.10 \pm 0.03$ & $0.09 \pm 0.01$ & 0.177 \\
\hline Conformity number & $0.64 \pm 0.09$ & $0.78 \pm 0.06$ & 0.01 \\
\hline $\begin{array}{l}\text { Ipsilateral lung } \\
\mathrm{V}_{5}(\%) \\
\mathrm{V}_{20}(\%) \\
\text { Mean dose [Gy] }\end{array}$ & $\begin{array}{c}59.34 \pm 18.82 \\
33.01 \pm 5.45 \\
17.82 \pm 3.00\end{array}$ & $\begin{array}{c}58.36 \pm 16.98 \\
33.07 \pm 5.50 \\
18.21 \pm 2.97\end{array}$ & $\begin{array}{l}0.538 \\
0.795 \\
0.276 \\
\end{array}$ \\
\hline $\begin{array}{l}\text { Contralateral lung } \\
\mathrm{V}_{5}(\%) \\
\mathrm{V}_{20}(\%) \\
\text { Mean dose }[\mathrm{Gy}]\end{array}$ & $\begin{array}{c}61.49 \pm 15.47 \\
18.95 \pm 9.98 \\
11.67 \pm 3.00\end{array}$ & $\begin{array}{c}61.57 \pm 14.87 \\
20.75 \pm 8.43 \\
11.84 \pm 2.96\end{array}$ & $\begin{array}{l}0.705 \\
0.586 \\
0.492\end{array}$ \\
\hline $\begin{array}{l}\text { Total lungs } \\
\mathrm{V}_{20}(\%) \\
\text { Mean dose }[\mathrm{Gy}]\end{array}$ & $\begin{array}{l}28.02 \pm 5.75 \\
16.00 \pm 2.80\end{array}$ & $\begin{array}{l}28.87 \pm 5.17 \\
16.24 \pm 2.74\end{array}$ & $\begin{array}{l}0.523 \\
0.332\end{array}$ \\
\hline $\begin{array}{l}\text { Heart } \\
\mathrm{V}_{30}(\%) \\
\mathrm{V}_{40}(\%) \\
\mathrm{V}_{50}(\%)\end{array}$ & $\begin{array}{c}11.99 \pm 12.86 \\
5.97 \pm 6.61 \\
2.35 \pm 2.95\end{array}$ & $\begin{array}{c}11.21 \pm 13.88 \\
4.66 \pm 5.95 \\
1.96 \pm 2.20\end{array}$ & $\begin{array}{l}0.326 \\
0.256 \\
0.701\end{array}$ \\
\hline $\begin{array}{l}\text { Spinal cord } \\
\text { Dmax [Gy] } \\
D_{2 \%}[G y] \\
\end{array}$ & $\begin{array}{l}36.79 \pm 3.84 \\
33.44 \pm 3.57\end{array}$ & $\begin{array}{l}34.92 \pm 6.11 \\
31.38 \pm 5.70 \\
\end{array}$ & $\begin{array}{l}0.098 \\
0.102 \\
\end{array}$ \\
\hline $\begin{array}{l}\text { Esophagus } \\
\text { Mean dose [Gy] }\end{array}$ & $23.33 \pm 7.86$ & $24.19 \pm 8.11$ & 0.124 \\
\hline Integral dose [Gy] & $168.01 \pm 50.06$ & $165.67 \pm 48.51$ & 0.758 \\
\hline
\end{tabular}

there are many conflicting results in the published literature about the differences in the clinical benefits of each IMRT technique. This current study was performed to compare the DVH indices between the HT and VMAT plans in locally advanced lung cancer cases with the intention of providing a basis for choosing the appropriate method of treatment in the clinic.

In the current study, both the HT and VMAT plans conceived satisfactory dosimetric results in terms of PTV dosage according to the clinical requirement criteria conducted from ICRU 83. Although the $\mathrm{D}_{2 \%}, \mathrm{D}_{50 \%}, \mathrm{D}_{98 \%}, \mathrm{~V}_{95}, \mathrm{~V}_{107}$, and $\mathrm{HI}$ values from both plans were almost identical, the mean $\mathrm{CN}$ value of VMAT was revealed to be non-significantly higher and closer to 1 than of the HT plan. This would infer that VMAT offered only a marginally greater dose distribution covering the
PTV volume with a lesser degree of radiation dose scattering to normal tissue outside PTV than the HT plan. These results were in accordance with the findings of a previous report submitted by Xhaferllari et al. [19] and Xu et al. [20] who made comprehensive comparisons of IMRT, VMAT, and HT planning for early stage and LA-NSCLC, respectively. They concluded that VMAT yielded better conformity than other techniques with conformity index values significantly closer to 1 . In contrast, a recent study conducted in Turkey [21], which compared the dosimetric results of $\mathrm{HT}$ and the hybrid (3DCRT-VMAT) technique in LA-NSCLC, reported comparable conformity index values but better HI results when using the HT technique. For the HT technique, many dosimetrists have expanded the technical margin around PTV to achieve better dose conformity. 


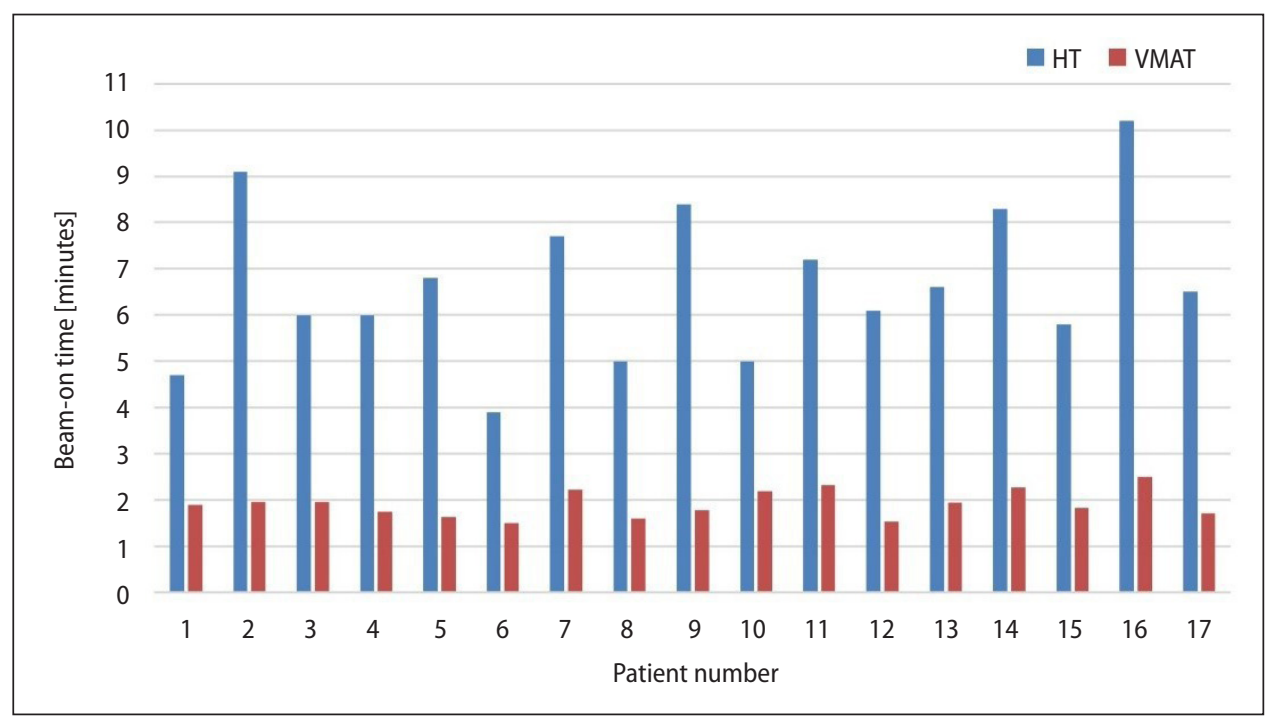

Figure 1. Beam-on time of helical tomotherapy $(\mathrm{HT})$ and volumetric modulated arc therapy (VMAT) plans for 17 patients

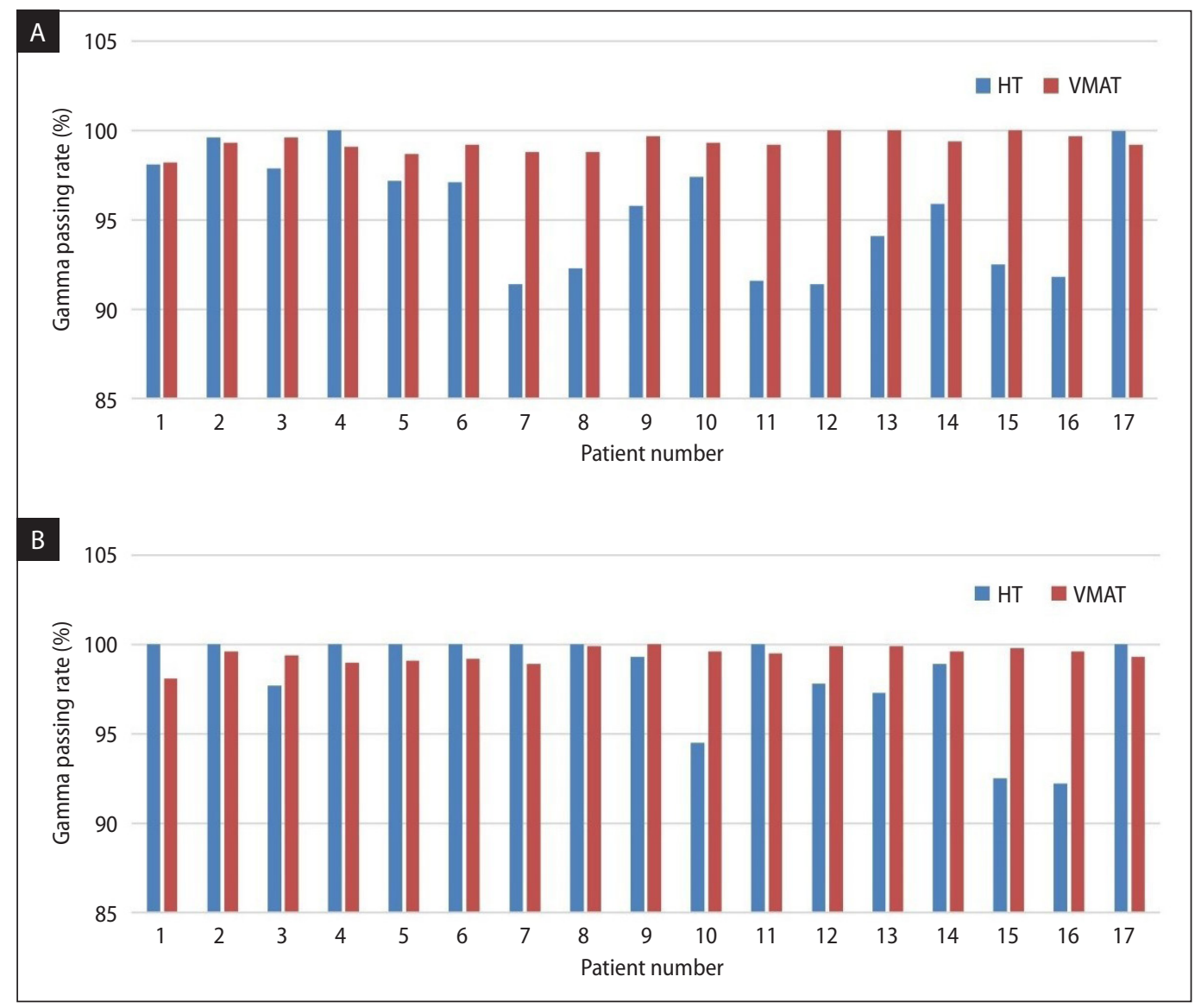

Figure 2. Gamma passing rate at $3 \% / 3 \mathrm{~mm}$ criteria of the helical tomotherapy $(\mathrm{HT})$ and volumetric modulated arc therapy (VMAT) plans by absolute dose (A) and relative dose (B)

Although our HT was planned without the addition of a technical margin, it could have made a difference in the $\mathrm{CN}$ values reported in our study. This variation in dose homogeneity and conformity also might have occurred as a result of a variety of factors such as the dose calculation 
algorithm that was used, collimator size, and the method of dose delivery.

About the radiation side effects to critical organs in the thorax region, all of our treatment plans were designed based on the RTOG 0617 dose constraint for OARs and have met all prescribed criteria. Symptomatic radiation pneumonitis is one of the most common side effects of radiation that can deteriorate the quality of life of a patient and ultimately be a cause of death. Previously published literature has revealed that the best predictor of radiation pneumonitis would be total lung $\mathrm{V}_{20}$ [22]. Later, other parameters, such as mean lung dose (MLD), lung $\mathrm{V}_{30}$, location of the tumor, and patient factors, were also found to be highly relevant $[23,24]$. The lung doses applied in both the HT and VMAT plans were acceptable with comparable mean total lung $\mathrm{V}_{20}(28.02 \%$ vs. $28.87 \%, \mathrm{p}=0.523)$ and mean MLD (16.00 vs. $16.24 \mathrm{~Gy}, \mathrm{p}=0.332)$ values. With a specified concentration in the ipsilateral lung dose, both radiation techniques still yielded a satisfactory result with $\mathrm{V}_{20}$ values of less than 35\% and MLD values of less than 20 Gy. All these lung dose parameters confirmed that both planning techniques could effectively minimize the risk of radiation pneumonitis.

Furthermore, the heart dose is another point of concern when radiotherapy is administered to the thoracic area. However, there is currently no consistent quantitative heart dose constraint recommendation. A number of studies conducted by Wang et al. [25], Dess et al. [26], and Speirs et al. [27] used the following heart dose constraints: $\mathrm{V}_{40}<100 \%, \mathrm{~V}_{40}<100 \%$ and $\mathrm{V}_{65}<33 \%$, and $\mathrm{V}_{50}<25 \%$, respectively. Speirs et al. [27] reported that heart dose is associated with OS and cardiac toxicity, while $V_{50}$ is considered to be one of the independent negative predictive factors for OS. When categorized by a heart $\mathrm{V}_{50}$ of less than $25 \%$, versus $25 \%$ or greater, the 1 and 2 -year OS rates between the two groups revealed statistically significant differences ( $70.2 \%$ vs. $46.8 \%$ and $45.9 \%$ vs. $26.7 \%, \mathrm{p}<0.0001$, respectively). Currently, it is believed that whole heart dosimetry is more crucial than a single parameter. With regard to recent evidence, we have analyzed the appropriate heart dose by 3 dose constraints $\left(\mathrm{V}_{30}, \mathrm{~V}_{40}\right.$, and $\left.\mathrm{V}_{50}\right)$ and found that both of our treatment planning techniques delivered a very low radiation dose to the heart, while there was a tendency to decrease the heart dose with the VMAT plan. The reduction in the heart dose from the VMAT plan might have been related to differences in the beam delivery techniques. While HT uses a rotating gantry to continuously move around the patient's body, VMAT can use a partial arc technique that can accurately deliver a radiation beam by avoiding some parts of the OARs. This minimal dosimetric difference also occurred with the spinal cord (Dmax and $\mathrm{D}_{2 \%}$ ), which can be spared by the partial arc technique of VMAT. However, even with different techniques for dose delivery, the integral dose for both techniques were almost identical.

In this study, the VMAT beam-on time was found to be significantly shorter than it was for Tomotherapy ( 1.91 vs. 6.66 minutes, $\mathrm{p}<0.001$ ) when correlating the results from the previously mentioned studies $[5,19]$. One study [19] found that the VMAT mean treatment time was 1.95 minutes and the HT time was 9.30 minutes $(\mathrm{p}<0.001)$. Shorter treatment times should be considered a strong advantage of VMAT, especially in the thoracic region, which is known to have a major problem with respiratory organ motion and intrafractionation motion during the course of treatment. Lung cancer patients, who cannot always tolerate long periods of treatment due to airway problems, will be able to receive satisfactory results with the shorter treatment times associated with VMAT. For HT planning, Piotrowski et al. [28] concluded that the amount of beam-on time clearly depends upon the planning parameters, while the beam-on time can be decreased by changing certain planning parameters such as MF, pitch, and field width. Nevertheless, overall treatment time as it relates to patient positioning, imaging, image registration, and radiation has not been fully determined. Despite being associated with a longer beam-on time, HT has a more seamless treatment process that might result in less differences in the overall treatment time when compared with VMAT.

During the actual treatment, HT and VMAT produced over modulations that might indicate that they were not flawlessly administered. The high degree of complexity for the radiation plan can initiate a discrepancy between the calculated dose and the delivered dose; therefore, PSQA is an essential process that must follow a complete plan of action to verify the accuracy of radiation delivery before the actual treatment. As the gamma index analysis is an advised 
method of PSQA for HT and VMAT [17, 18, 29, 30], we have measured $3 \% / 3 \mathrm{~mm}$ with a $10 \%$ threshold for both absolute and relative radiation doses. Our results revealed that every plan for both the HT and VMAT had a satisfactory GPR value (of more than 90\%). This can indicate that the planning algorithms and treatment machines of both techniques are sufficient and reliable in treating a patient with a complex tumor-like locally advanced case of lung cancer.

In recent times, there have also been many additional processes that have led to highly precise treatments. In this study, we used the 4D-CT simulation with MIP image, which accounts for tumor motion, to produce the smallest possible iGTV value. If the gating system is added to VMAT or the tracking system is added to HT in the actual treatment, the PTV margin can be reduced to less than $5 \mathrm{~mm}$ and this can result in easier and better treatment planning. Another limitation of our study is that we only made comparisons between particular HT and VMAT planning techniques. VMAT can be planned with different techniques such as a full arc technique or a non-coplanar technique, while HT can use the TomoDirect technique that may produce various dosimetric results. Additionally, tumor size and location are important factors that should be considered for treatment technique selection. A future study should be conducted that focuses on the association between the tumor factors and the dosimetric results obtained from each technique.

\section{Conclusion}

Both HT and VMAT techniques created clinical satisfactory and reliable radiation treatment plans without any significant differences in critical organ dosimetry. However, the VMAT plan exhibited non-significantly better degrees of conformity and significantly shorter treatment times. Consequently, these preferences indicate that VMAT would be a preferred choice for LA-NSCLC.

None declared.

\section{Acknowledgements}

\section{Conflicts of interest}

None declared.

\section{Funding}

None declared.

\section{References}

1. Perez C, Pajak T, Rubin P, et al. Long-term observations of the patterns of failure in patients with unresectable non-oat cell carcinoma of the lung treated with definitive radiotherapy report by the radiation therapy oncology group. Cancer. 1987; 59(11): 1874-1881, doi: 10.1002/1097-0142(19870601)59:11<1874::aidcncr2820591106>3.0.co;2-z, indexed in Pubmed: 3032394.

2. Choi N, Doucette J. Improved survival of patients with unresectable non-small-cell bronchogenic carcinoma by an innovated high-doseEn-Bloc radiotherapeutic approach. Cancer. 1981; 48(1): 101-109, doi: 10.1002/1097-0142(19810701)48:1<101::aidcncr2820480120>3.0.co;2-s, indexed in Pubmed: 6263449.

3. Chun SG, Hu C, Choy H, et al. Impact of Intensity-Modulated Radiation Therapy Technique for Locally Advanced Non-Small-Cell Lung Cancer: A Secondary Analysis of the NRG Oncology RTOG 0617 Randomized Clinical Trial. J Clin Oncol. 2017;35(1):56-62, doi: 10.1200/JCO.2016.69.1378, indexed in Pubmed: 28034064.

4. Cattaneo GM, Dell'oca I, Broggi S, et al.Treatment planning comparison between conformal radiotherapy and helical tomotherapy in the case of locally advanced-stage NSCLC. Radiother Oncol. 2008; 88(3): 310-318, doi: 10.1016/j. radonc.2008.06.006, indexed in Pubmed: 18692266.

5. Jiang X, Li T, Liu Y, et al. Planning analysis for locally advanced lung cancer: dosimetric and efficiency comparisons between intensity-modulated radiotherapy (IMRT), single-arc/partial-arc volumetric modulated arc therapy (SA/PA-VMAT). Radiat Oncol. 2011; 6: 140, doi: 10.1186/1748-717X-6-140, indexed in Pubmed: 22014217.

6. Piotrowski T, Skórska M, Jodda A, et al. Tomotherapy - a different way of dose delivery in radiotherapy. Contemp Oncol (Pozn). 2012; 16(1): 16-25, doi: 10.5114/ wo.2012.27332, indexed in Pubmed: 23788850.

7. Balog J, Mackie TR, Pearson D, et al. Benchmarking beam alignment for a clinical helical tomotherapy device. Med Phys. 2003; 30(6): 1118-1127, doi: 10.1118/1.1576395, indexed in Pubmed: 12852536.

8. Otto K. Volumetric modulated arc therapy: IMRT in a single gantry arc. Med Phys. 2008; 35(1): 310-317, doi: 10.1118/1.2818738, indexed in Pubmed: 18293586.

9. Bertelsen A, Hansen CR, Johansen J, et al. Single Arc Volumetric Modulated Arc Therapy of head and neck cancer. Radiother Oncol. 2010; 95(2): 142-148, doi: 10.1016/j. radonc.2010.01.011, indexed in Pubmed: 20188427.

10. Quan EM, Li X, Li Y, et al. A comprehensive comparison of IMRT and VMAT plan quality for prostate cancer treatment. Int J Radiat Oncol Biol Phys. 2012; 83(4): 1169-1178, doi: 10.1016/j.jirobp.2011.09.015, indexed in Pubmed: 22704703.

11. Kryger M, Wang W, Wu S, et al. A Comparison of IMRT and VMATTreatment Planning for Head and Neck Cancer With NTCP/TCP Analysis. Int J Radiat Oncol Biol Phys. 2017; 99(2): E680, doi: 10.1016/j.jirobp.2017.06.2242.

12. Adamczyk M, Konkol M, Matecka-Nowak M, et al. 4DCT-based evaluation of lung tumour motion during the breathing cycle. Neoplasma. 2020; 67(1): 193-202, doi: 10.4149/neo_2019_190309N206, indexed in Pubmed: 31847524. 
13. Yoon M, Park SY, Shin D, et al. A new homogeneity index based on statistical analysis of the dose-volume histogram. J Appl Clin Med Phys. 2007; 8(2): 9-17, doi: 10.1120/ jacmp.v8i2.2390, indexed in Pubmed: 17592460.

14. Riet A, Mak A, Moerland M, et al. A conformation number to quantify the degree of conformality in brachytherapy and external beam irradiation: Application to the prostate. Int J Radiat Oncol Biol Phys. 1997; 37(3): 731-736, doi: 10.1016/s0360-3016(96)00601-3, indexed in Pubmed: 9112473.

15. Bradley J, Paulus R, Komaki R, et al. Standard-dose versus high-dose conformal radiotherapy with concurrent and consolidation carboplatin plus paclitaxel with or without cetuximab for patients with stage IIIA or IIIB non-smallcell lung cancer (RTOG 0617): a randomised, two-bytwo factorial phase 3 study. Lancet Oncol. 2015; 16(2): 187-199, doi: 10.1016/s1470-2045(14)71207-0, indexed in Pubmed: 25601342.

16. Jodda A, Piotrowski T, Kruszyna-Mochalska M, et al. Impact of different optimization strategies on the compatibility between planned and delivered doses during radiation therapy of cervical cancer. Rep Pract Oncol Radiother. 2020; 25(3): 412-421, doi: 10.1016/j.rpor.2020.03.027, indexed in Pubmed: 32372881.

17. Ezzell GA, Burmeister JW, Dogan N, et al. IMRT commissioning: multiple institution planning and dosimetry comparisons, a report from AAPM Task Group 119. Med Phys. 2009; 36(11): 5359-5373, doi: 10.1118/1.3238104, indexed in Pubmed: 19994544.

18. Langen KM, Papanikolaou N, Balog J, et al. AAPM Task Group 148. QA for helical tomotherapy: report of the AAPM Task Group 148. Med Phys. 2010; 37(9): 4817-4853, doi: 10.1118/1.3462971, indexed in Pubmed: 20964201.

19. Xhaferllari I, El-Sherif O, Gaede S. Comprehensive dosimetric planning comparison for early-stage, non-small cell lung cancer with SABR: fixed-beam IMRT versus VMAT versus TomoTherapy. J Appl Clin Med Phys. 2016; 17(5): 329-340, doi: 10.1120/jacmp.v17i5.6291, indexed in Pubmed: 27685129.

20. Xu Y, Deng W, Yang S, et al. Dosimetric comparison of the helical tomotherapy, volumetric-modulated arc therapy and fixed-field intensity-modulated radiotherapy for stage IIB-IIIB non-small cell lung cancer. Sci Rep. 2017; 7(1): 14863, doi: 10.1038/s41598-017-14629-w, indexed in Pubmed: 29093491.

21. Temelli Ö, Demirtas M, Ugurlu B. Dosimetric comparison of helical tomotherapy and hybrid (3DCRT-VMAT) technique for locally advanced non-small cell lung cancer.
J Radiother Pract. 2020; 20(3): 300-305, doi: 10.1017/ s1460396920000357.

22. Graham M, Purdy J, Emami B, et al. Clinical dose-volume histogram analysis for pneumonitis after 3D treatment for non-small cell lung cancer (NSCLC). Int J Radiat Oncol Biol Phys. 1999; 45(2): 323-329, doi: 10.1016/s03603016(99)00183-2, indexed in Pubmed: 10487552.

23. Kim TH, Cho KHo, Pyo HR, et al. Dose-volumetric parameters for predicting severe radiation pneumonitis after three-dimensional conformal radiation therapy for lung cancer. Radiology. 2005; 235(1): 208-215, doi: 10.1148/ radiol.2351040248, indexed in Pubmed: 15703313.

24. Palma DA, Senan S, Tsujino K, et al. Predicting radiation pneumonitis after chemoradiation therapy for lung cancer: an international individual patient data meta-analysis. Int J Radiat Oncol Biol Phys. 2013; 85(2): 444-450, doi: 10.1016/j.ijrobp.2012.04.043, indexed in Pubmed: 22682812.

25. Wang K, Eblan MJ, Deal AM, et al. Cardiac Toxicity After Radiotherapy for Stage III Non-Small-Cell Lung Cancer: Pooled Analysis of Dose-Escalation Trials Delivering 70 to 90 Gy. J Clin Oncol. 2017; 35(13): 1387-1394, doi: 10.1200/ JCO.2016.70.0229, indexed in Pubmed: 28113017.

26. Dess RT, Sun Y, Matuszak MM, et al. Cardiac Events After Radiation Therapy: Combined Analysis of Prospective Multicenter Trials for Locally Advanced Non-Small-Cell Lung Cancer. J Clin Oncol. 2017; 35(13): 1395-1402, doi: 10.1200/ JCO.2016.71.6142, indexed in Pubmed: 28301264.

27. Speirs CK, DeWees TA, Rehman S, et al. Heart Dose Is an Independent Dosimetric Predictor of Overall Survival in Locally Advanced Non-Small Cell Lung Cancer. J Thorac Oncol. 2017; 12(2): 293-301, doi: 10.1016/j. jtho.2016.09.134, indexed in Pubmed: 27743888.

28. Piotrowski T, Czajka E, Bak B, et al. Tomotherapy: implications on daily workload and scheduling patients based on three years' institutional experience. Technol Cancer Res Treat. 2014; 13(3): 233-242, doi: 10.7785/tcrt.2012.500374, indexed in Pubmed: 24066951.

29. Low DA, Dempsey JF. Evaluation of the gamma dose distribution comparison method. Med Phys. 2003; 30(9): 2455-2464, doi: 10.1118/1.1598711, indexed in Pubmed: 14528967.

30. Jodda A, Piotrowski T, Kruszyna-Mochalska M, et al. Impact of different optimization strategies on the compatibility between planned and delivered doses during radiation therapy of cervical cancer. Rep Pract Oncol Radiother. 2020; 25(3): 412-421, doi: 10.1016/j.rpor.2020.03.027, indexed in Pubmed: 32372881. 